\title{
Subcarinal Lymph Node
}

National Cancer Institute

\section{Source}

National Cancer Institute. Subcarinal Lymph Node. NCI Thesaurus. Code C117873.

A lymph node located in the thoracic cavity between the lungs. It is bordered by the carina

of the trachea, lower lobe bronchus on the left and the bronchus intermedius on the right. 